\title{
RETRATO DE UMA DÉCADA DE PESQUISA DO POSCOM/UFSM: UM OLHAR PARA A PRODUÇÃO CIENTÍFICA DA LINHA MÍDIA E ESTRATÉGIAS COMUNICACIONAIS
}

Portrait of a decade of Poscom/UFSM's research: a view towards the scientific production of the media and communication strategies line of research

Retrato de una decada de investigación de Poscom/UFSM: una mirada a la producción científica de la línea medio y estrategias de comunicación

Maria Ivete Trevisan Fossá Professora do Programa de Pós-Graduação em Comunicação da Universidade Federal de Santa Maria (UFSM) fossa@terra.com.br

Mateus da Cunha Santos Mestre em Comunicação pelo Programa de Pós-Graduação em Comunicação da UFSM mateuscunha90@gmail.com

Gustavo David Araújo Freire Doutorando no Programa de Pós-Graduação em Comunicação da UFSM gustavofreire.rp@hotmail.com

Kauane Andressa Müller Mestra em Comunicação pelo Programa de Pós-Graduação em Comunicação da UFSM kauaneamuller@gmail.com

Amanda Frick Martins Doutoranda no Programa de Pós-Graduação em Comunicação da UFSM rp.amandafrick@gmail.com

Solange Prediger Doutoranda no Programa de Pós-Graduação em Comunicação da UFSM sol_prediger@yahoo.com.br

Gibsy Lisiê Soares Caporal Doutoranda no Programa de Pós-Graduação em Comunicação da UFSM gibsy.caporal@iffaroupilha.edu.br

Taisa Ferro Dalla Valle Doutoranda no Programa de Pós-Graduação em Comunicação da UFSM taisa@dallavalle.net.br 


\title{
Resumo
}

Este artigo tem o objetivo de retratar a produção científica da linha de pesquisa Mídia e Estratégias Comunicacionais, do Programa de Pós-Graduação em Comunicação, da Universidade Federal de Santa Maria (UFSM), referente à sua primeira década de produção efetiva (2008-2017). Através do método desk research, 49 dissertações e 12 teses foram avaliadas por um grupo de oito pesquisadores. A análise revelou uma unanimidade de estudos empíricos e uma predominância de pesquisas de tipo qualitativo $(96,7 \%)$ e natureza exploratória (95\%). Na pesquisa ainda foram exploradas particularidades como a apresentação da questão de pesquisa, hipóteses, objetivos e justificativa, o referencial teórico, as abordagens metodológicas, as indicações dos limites dos estudos e recomendações para pesquisas futuras.

Palavras-chave: Produção científica. Mídia e Estratégias Comunicacionais. Poscom/UFSM.

\begin{abstract}
This article aims to characterize the scientific production of the Media and Communication Strategies line of research of the Postgraduate Program in Communication at Federal University of Santa Maria (UFSM), referring to its first decade of effective production (20082017). Through desk research method, 49 dissertations and 12 theses were evaluated by a group of eight researchers. The analysis revealed an unanimity of empirical studies and a predominance of qualitative $(96.7 \%)$ and exploratory research $(95 \%)$. The study also approached particularities such as the presentation of the research question, hypotheses, objectives and justification, the theoretical framework, the methodological approaches, the indications of the limits of the studies and the recommendations for future research.
\end{abstract}

Key words: Scientific production. Media and Communication Strategies. Poscom/UFSM.

\section{Resumen}

Este artículo tiene como objetivo retratar la producción científica de la línea de investigación Medio y Estrategias de Comunicación, del Programa de Postgrado en Comunicación, de la Universidad Federal de Santa María (UFSM), en referencia a su primera década de producción efectiva (2008-2017). Mediante el método desk research, un grupo de ocho investigadores evaluó 49 disertaciones y 12 tesis. El análisis reveló una unanimidad de estudios empíricos y un predominio de investigación cualitativa (96.7\%) y exploratoria $(95 \%)$. El estudio también exploró particularidades como la presentación de la pregunta de investigación, hipótesis, objetivos y justificación, lo referencial teórico, los enfoques metodológicos, las indicaciones de los límites de los estudios y las recomendaciones para futuras investigaciones.

Palabras clave: Producción científica. Medio y Estrategias de Comunicación.Poscom/UFSM. 


\section{INTRODUÇÃO}

O Programa de Pós-Graduação em Comunicação (Poscom) da Universidade Federal de Santa Maria (UFSM) foi recomendado pela Comissão de Aperfeiçoamento de Pessoal Docente, da Coordenação de Aperfeiçoamento de Pessoal de Nível Superior (CAPES), em 17 de setembro de 2005. No mês seguinte, o programa iniciou o processo de seleção de discentes para o curso de Mestrado em Comunicação. Em dezembro, ocorreu o primeiro Seminário de Credenciamento, no qual foram arrolados oito docentes do Departamento de Ciências da Comunicação do Campus Sede da UFSM.

No dia 5 de março de 2006, foram iniciadas as aulas do curso, mostrando a força da proposta que resultou na criação do primeiro programa de pós-graduação em comunicação inserido em uma universidade pública localizada no interior da região Sul do Brasil. Desde então, o Poscom tem atendido a demanda de geração de conhecimento especializado no campo de comunicação, promovendo a qualificação de docentes e pesquisadores, tanto do Brasil quanto de países vizinhos e outros continentes.

Desde sua implantação, o Programa tem buscado seguir a política de área da CAPES quanto à proposta, às práticas de pesquisa, às atividades de formação, ao corpo discente, às teses e dissertações, à produção intelectual e à inserção temática na área do conhecimento. $\mathrm{Na}$ primeira avaliação trienal a qual foi submetido, referente ao ano de 2010, o Poscom recebeu conceito de excelência 4. No ano seguinte, a CAPES aprovou a implementação do curso de Doutorado em Comunicação da UFSM, tendo sido um dos primeiros, na área, a ser criado em uma cidade localizada no interior do Brasil. Em 2013, ao final do segundo ano letivo do curso, o Programa passou ao conceito de excelência 5.

O Poscom conta atualmente com 18 docentes permanentes e 4 professores colaboradores, agregando pesquisas que trabalham com a gestão da comunicação e modelos de comunicação institucional; novas formas de suportes e ambientes comunicacionais; dimensões macro analíticas da indústria cultural e seus efeitos na realidade social; relações da cultura das mídias com temporalidades e espacialidades; mídia e efeitos de sentido; mídia e espaço público; suportes midiáticos; estratégias de comunicação organizacional e institucional; linguagens visuais e produção de sentido.

A estruturação do programa se funda em uma área de concentração denominada Comunicação Midiática, que, conforme consta na Análise das Propostas de Cursos Novos, "compreende o estudo da ação midiática implicada na estruturação do espaço público, na visibilidade e legitimação das instituições e na configuração das identidades contemporâneas" 
(CAPES, 2006). Nesse sentido, ocupa-se, prioritariamente, de estudar as formas através das quais os meios de comunicação social massivos incidem na associação, configuração e solidificação das relações sociais no tempo e no espaço.

A área de concentração em Comunicação Midiática congrega dois conjuntos de estudos definidos como linhas de pesquisa: Mídia e Identidades Contemporâneas e Mídia e Estratégias Comunicacionais.

A linha de pesquisa Mídia e Estratégias Comunicacionais, que é objeto deste estudo, faz referência às estratégias que agem como promotoras da articulação e de organização entre a esfera midiática e os demais campos sociais. Essas estratégias envolvem as relações do campo das mídias com os demais campos, especialmente as estratégias que este campo aciona ou dele são tomadas como empréstimo, para construir o espaço público contemporâneo, para assegurar a presença das instituições no espaço público e para instituir formas de vínculo social entre as instituições e os usuários de suas ofertas.

Os integrantes do Núcleo Docente (NPD) da linha de Pesquisa Mídia e Estratégias Comunicacionais são: Aline Roes Dalmolin, Carlise Porto Schneider Rudnicki, Eugenia Mariano da Rocha Barichello, Juliana Petermann, Maria Ivete Trevisan Fossá, Rejane de Oliveira Pozobon, Sandra Rúbia da Silva e Viviane Borelli. O núcleo conta, ainda, com duas professoras colaboradoras: Laura Strelow Storch e Maria Lília Dias de Castro.

Neste artigo, apresentamos os resultados obtidos através de uma análise estrutural das teses e dissertações concluídas pelos discentes da linha de pesquisa Mídia e Estratégias Comunicacionais, entre 2008 e 2017. Primeiramente, discorremos sobre o método aplicado, em seguida, apresentamos os resultados do estudo. Por fim, expressamos as principais conclusões oriundas das descobertas evidenciadas pela análise.

\section{MÉTODO APLICADO}

O procedimento metodológico utilizado foi o desk research ${ }^{l}$, envolvendo o conjunto de dissertações e teses defendidas na linha de pesquisa Mídia e Estratégias Comunicacionais, do Programa de Pós-Graduação em Comunicação da UFSM, no período de 2008 a 2017.

O processo de identificação e seleção das teses e dissertações resultou em uma relação de 62 dissertações referentes ao período de 2008 a 2017 e 14 teses do período de 2015 a 2017. O total de 76 trabalhos foi submetido a alguns critérios de seleção como: a) tese ou

\footnotetext{
${ }^{1}$ Desk research consiste em uma pesquisa exploratória através da coleta e uso de informações já publicadas e disponíveis.
} 
dissertação considerada, efetivamente, na área de concentração do programa, na linha de pesquisa Mídia e Estratégias Comunicacionais; b) conter a palavra "estratégia" em pelo menos um dos seguintes itens: título, resumo, palavras-chave e sumário. Esse último recorte se mostrou necessário a partir da constatação de que, apesar de estar inserida na linha de pesquisa Mídia e Estratégias Comunicacionais, uma parcela significativa dos trabalhos sequer menciona o termo "estratégia" nos itens mencionados, o que pode indicar uma falta de aderência à temática proposta pelo Programa.

A aplicação desses critérios às 62 dissertações e 14 teses defendidas no período delimitado resultou em 61 trabalhos, sendo 49 dissertações e 12 teses. Observa-se que 13 pesquisas de mestrado e duas de doutorado foram excluídas da análise, por não atenderem ao segundo critério estabelecido.

Após delimitarmos o corpus de pesquisa, partimos para a definição do processo de análise dos trabalhos, que consistiu na verificação de categorias analíticas, considerando: a) objeto de pesquisa; b) tipo de pesquisa (qualitativa, quantitativa); c) natureza da pesquisa (exploratória, descritiva ou explicativa); d) questão de pesquisa (presente ou ausente); e) hipóteses (presentes ou ausentes); f) objetivo geral (presente ou ausente); g) justificativa (presente ou ausente); h) referencial teórico; i) metodologia; j) descrição dos procedimentos metodológicos (presente ou ausente); k) técnicas de coletas de dados; 1) validade de conteúdo dos instrumentos (presente ou ausente); m) apresentação de limites do estudo; n) recomendações para pesquisas futuras.

A avaliação dessas categorias de análise foi realizada por um grupo de oito pesquisadores, membros do Grupo de Pesquisa Comunicação Institucional e Organizacional/CNPq, vinculado à linha de pesquisa Mídia e Estratégias Comunicacionais, sendo que cada trabalho foi examinado por mais de um avaliador. Para darem conta da análise das categorias estabelecidas, os pesquisadores buscaram fundamentação teórica e realizaram uma ampla discussão entre os membros do grupo, em busca de uma maior validade para o estudo. Os dados coletados através de formulários padronizados foram tabulados e processados através do software Excel.

\section{RESULTADOS DA PESQUISA}

Para compor uma visão geral em relação ao corpus analisado, — respeitando os critérios de seleção estabelecidos — no quadro abaixo, apresentamos a distribuição da periodicidade das 61 dissertações e teses concluídas no período de 2008 a 2017. 


\begin{tabular}{|c|c|c|c|}
\hline Ano de publicação & Dissertações & Teses & Total \\
\hline 2008 & 6 & 0 & 6 \\
\hline 2009 & 5 & 0 & 5 \\
\hline 2010 & 4 & 0 & 4 \\
\hline 2011 & 6 & 0 & 6 \\
\hline 2012 & 7 & 0 & 7 \\
\hline 2013 & 5 & 0 & 6 \\
\hline 2014 & 6 & 0 & 12 \\
\hline 2015 & 8 & 4 & 3 \\
\hline 2016 & $0^{2}$ & 3 & 7 \\
\hline 2017 & 2 & 5 & \\
\hline
\end{tabular}

Tabela 1 - Distribuição da periodicidade do corpus de análise

Fonte: elaborada pelos autores.

Na sequência, apresentaremos as descobertas evidenciadas pela pesquisa, conforme a seguinte ordem: objetos; tipos e naturezas das pesquisas; questão de pesquisa, hipóteses, objetivos e justificativas; referencial teórico; métodos e técnicas de coleta de dados; limites dos estudos e recomendações para pesquisas futuras.

\subsection{Objetos de pesquisa}

No campo da comunicação, observa-se uma imensa diversidade de temas, objetos, questões, ângulos, conceitos, paradigmas e teorias que hoje são acionados, conforme as escolas, áreas de interesse e linhas de pesquisa. Por isso a importância da realização de pesquisas que solicitem respostas sobre aspectos de uma determinada situação, por meio de pesquisas empíricas, cuja escolha e construção dos objetos devem estar orientadas por teorias pertinentes. Nesse sentido, concordamos com Braga (2001, p. 2), quando afirma que

diferentes pesquisas solicitam diferentes aproximações, conforme suas perguntas e objetos; e mesmo táticas metodológicas comprovadas e pertinentes devem ser ajustadas a características concretas do objeto e ao desenho específico da investigação.

A definição do objeto compreende a primeira fase da pesquisa empírica, organizada por intervenções de caráter teórico, realizadas em função do fenômeno de comunicação que se quer pesquisar. As intervenções nessa primeira fase dizem respeito à formulação do problema de pesquisa, o quadro teórico de referência, a justificativa, os objetivos e as hipóteses. As teorias que adotamos envolvem tanto explicações da realidade como também fornecem os

\footnotetext{
${ }^{2}$ Dados os filtros estabelecidos para o recorte de trabalhos analisados, em 2014, há registro de três discentes (de um total de seis) que ingressaram na linha de pesquisa Mídia e Estratégias Comunicacionais. Com previsão de término para o início do ano de 2016, todos eles anteciparam a defesa, acontecendo no ano anterior. Fato que explica o número de defesas, em 2016, ser igual a zero.
} 
objetos tipo que em seu âmbito são constituídos e alguma ordem de questões que lhes são dirigidas e resultam na construção do objeto de pesquisa, orientando os conceitos a serem adotados, as premissas e hipóteses (BRAGA, 2011). Assim, o quadro de referência acaba delimitando teoricamente o problema de pesquisa e os alvos de toda a investigação (LOPES, 1990).

Nas dissertações e teses analisadas, verificamos que das 31 que efetivamente apresentam o conceito de estratégia ${ }^{3}$, todas são pesquisas empíricas, contemplando um total de 113 objetos. Para fins de análise, os objetos de pesquisa foram organizados em nove categorias temáticas. São elas: acontecimento; campanha eleitoral; empresas privadas; grupo musical; organizações do terceiro setor; organizações públicas; organizações religiosas; organizações de mídia; instituições de ensino. A categoria mais expressiva é a de organizações de mídia, representando $40,7 \%$ do corpus. Alguns desses estudos fazem referências ao Grupo RBS, aos jornais Folha de São Paulo, O Estado de São Paulo, Zero Hora, Diário de Santa Maria e A Razão, às emissoras de televisão TV Globo, TV Record, TV Santa Maria, às emissoras de rádio CBN e Radiocom FM, e às revistas Veja e Exame.

$\mathrm{Na}$ sequência, em segundo lugar, aparecem as empresas privadas, como a Natura, e marcas como a Havaianas e a Skol. Na terceira colocação estão as organizações públicas, como a Petrobrás e o Instituto Ethos.

Com relação ao objeto empírico, convém salientar que não é necessário que

as descobertas realizadas nas pesquisas empíricas se caracterizem como a vanguarda do conhecimento na área. [...] Se todo o trabalho de pesquisa corresponder apenas a elaborações dedutivas e ensaísticas - mesmo sofisticadas - a partir do que outros autores escreveram, faltará esse aspecto fundamental à experiência de nossos mestrandos e doutorandos (BRAGA, 2011, p. 6).

A afirmação do autor é suficiente para defender a ida do pesquisador ao campo, para buscar esclarecimentos mesmo que elementares e singulares, mas que, de algum modo, acrescentam novos olhares, ângulos e formas de interpretar a realidade, sem descartar insights ou fugir da fundamentação teórica que orienta o olhar sobre o objeto.

\footnotetext{
3 Diferentemente das demais categorias analíticas, para a avaliação dos objetos, contemplamos apenas os trabalhos que apresentam o conceito de "estratégia" em suas discussões teóricas, conforme resultado evidenciado pela etapa de análise do Referencial Teórico.
} 


\subsection{Tipos e naturezas das pesquisas}

No tocante à classificação das pesquisas, avaliamos os tipos e naturezas das dissertações e teses da linha de Mídia e Estratégias Comunicacionais. Nesse processo, observamos a predominância do tipo de pesquisa qualitativa, correspondendo a 96,7\% das publicações, e a inexistência de pesquisas exclusivamente quantitativas, o que parece refletir as características dos estudos na área de comunicação no Brasil. Destacamos, também, o baixo índice de pesquisas que combinam os dois tipos $(3,2 \%)$.

Já a natureza da pesquisa foi classificada em exploratória, descritiva ou explicativa, conforme Gil (1994) e Triviños (1994). Uma pesquisa exploratória se justifica quando o interesse é o de aprofundar conceitos preliminares. Seu objetivo básico é explorar o problema a fim de torná-lo explícito e possibilitar a criação de hipóteses. As teses e dissertações de natureza exploratória representam 58 das 61 pesquisas realizadas (95\%), enquanto as três restantes possuem caráter descritivo. Também observamos a ausência de procedimentos de amostragem e técnicas quantitativas de coleta de dados. Esse resultado indica que, na área da comunicação, o interesse consiste mais em realizar pesquisas aproximativas de determinado fenômeno comunicacional do que em formular hipóteses precisas e operacionalizáveis, muito comum nas pesquisas descritivas. Ademais, destacamos a ausência de pesquisas explicativas, com o objetivo de explicar o porquê dos fatos e esclarecer os fatores determinantes de um fenômeno ou evento na área de comunicação midiática. Sobre essa questão, cabe evidenciar que o dado obtido não surpreende, na medida em que pesquisas explicativas são comumente características das ciências ditas "duras".

\subsection{Questão de pesquisa, Hipóteses, Objetivo e Justificativa}

Em se tratando dos aspectos fundamentais que dão formato à pesquisa, destacam-se o problema, as hipóteses e os objetivos. Em conjunto com a justificativa, esses elementos são recuperados do projeto e apresentam uma visão geral ao leitor do que esperar do trabalho, dadas as informações preliminares estruturadas.

Nas teses e dissertações que compõem o corpus analisado, conforme mostra o Gráfico 1, retratamos a presença ou não desses elementos, que serão discutidos nessa mesma sequência. 


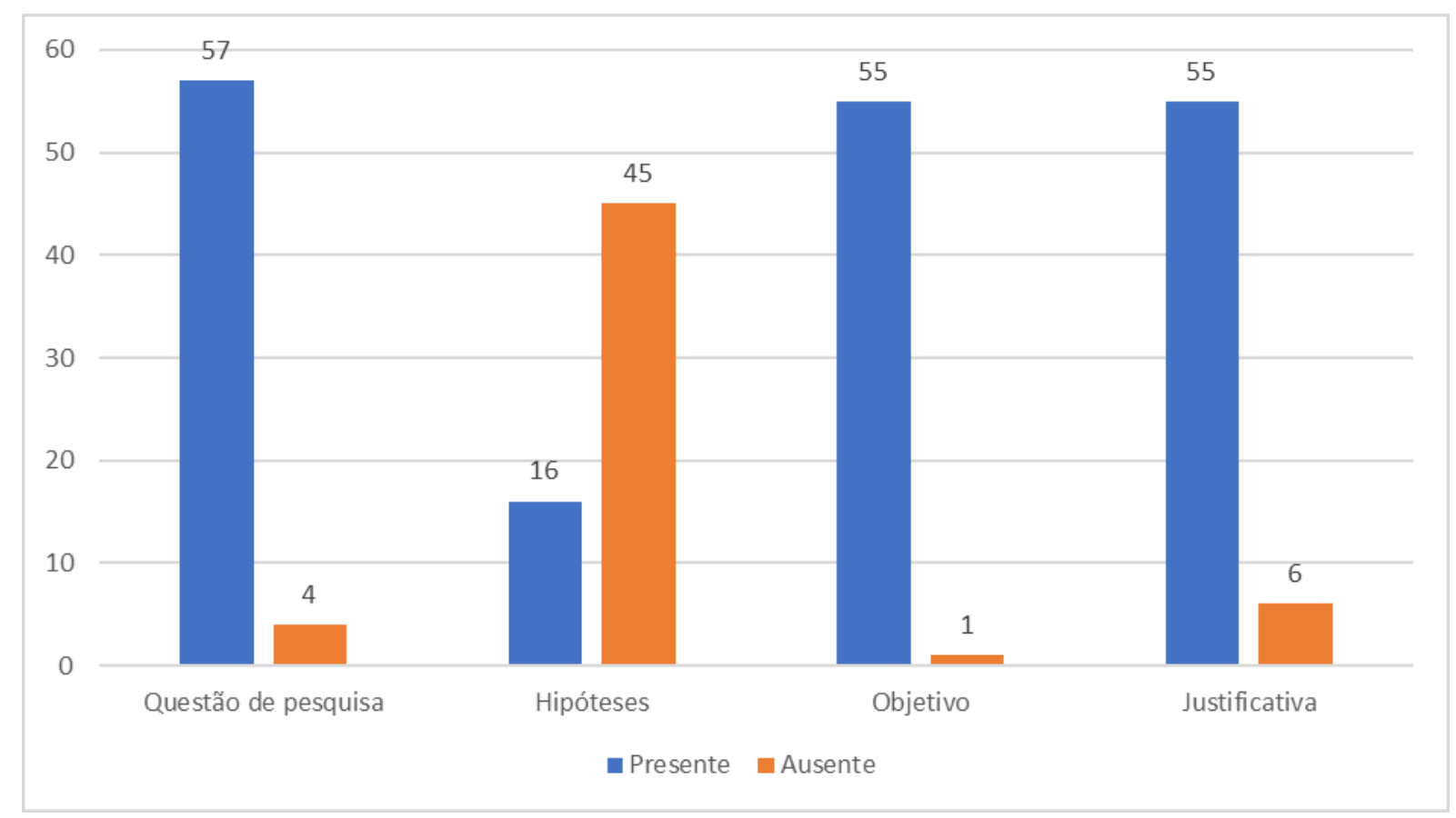

Gráfico 1 - Apresentação da Questão de pesquisa, Hipóteses, Objetivo e Justificativa

Fonte: elaborado pelos autores.

O problema de pesquisa é o ponto de partida de uma investigação científica. Ele é constituído pelo pesquisador e surge de um tema específico, que traz consigo uma problemática vinculada a um modelo teórico, diante do qual são construídas perguntas específicas de investigação. Costuma-se partir de um problema abrangente até chegar a uma pergunta-chave capaz de ser respondida pela investigação. Nas teses e dissertações avaliadas, verificamos a presença ou não de uma questão de pesquisa em cada uma. Essa tarefa resultou na constatação de que, dos 61 trabalhos analisados, apenas quatro não a apresentam (4,9\%). Apesar de representarem uma pequena parcela da produção acadêmica da linha de pesquisa do programa, julgamos pertinente salientar que a ausência de uma questão que sintetize a problemática de pesquisa pode comprometer a relevância de um estudo científico, na medida em que a ciência é, inerentemente, movida por indagações. Ademais, a ausência de uma questão-chave de pesquisa pode indicar que o pesquisador já iniciou sua investigação possuindo a resposta buscada, o que coloca em xeque a pertinência de sua pesquisa.

Quanto às hipóteses, observamos que estas são apresentadas em 16 trabalhos, correspondendo a 26,2\%, sendo que oito são teses. A ausência de hipóteses em estudos científicos é característica da área de comunicação e de pesquisas do tipo qualitativa. Não obstante, se nas pesquisas qualitativas as perguntas e os objetivos substituem a função das hipóteses, concordamos com Braga (2011, p. 12) quando afirma que "se não precisamos de hipóteses, difícil é não tê-las; mais difícil ainda seria se livrar das que nos surgem tão logo 
começamos a prefigurar um projeto de pesquisa". As hipóteses funcionam como bússolas, surgem na forma de insights sobre o objeto, na forma de visadas teóricas, ou por meio das relações desenvolvidas entre a abstração teórica e a observação da realidade.

Já os objetivos da pesquisa resultam da formulação do problema, compondo, com este, o eixo da investigação. Eles são frequentemente organizados em dois patamares: gerais e específicos. Os objetivos gerais correspondem às questões de horizonte teórico; já os objetivos específicos apresentam caráter mais concreto e desempenham uma função intermediária e instrumental que permite, de um lado, atingir o objetivo geral e, de outro, auxiliar no modo de operacionalizar metodologicamente a pesquisa. Nas teses e dissertações analisadas, constatamos que somente 1 trabalho não apresenta o seu objetivo geral.

O Instituto Nacional de Estudos Pedagógicos Anísio Teixeira apresenta uma série de verbos utilizados na elaboração dos objetivos, com os seus respectivos significados (BRASIL, 2010). A partir dessa relação, observamos os verbos mais utilizados na produção de objetivos (geral e específicos) dos trabalhos. Os verbos mais usados foram: analisar: decompor o todo em suas partes, observar, examinar com minúcia, submeter à crítica, examinar criticamente; argumentar: apresentar fatos, razões, provas contra ou a favor de algo. Defender ou contrapor pontos de vista; associar: estabelecer uma correspondência entre; caracterizar: por em evidência o caráter de, assinalar, distinguir, descrever; comparar: examinar simultaneamente a fim de conhecer as semelhanças, as diferenças ou relações; conhecer: ter noção, conhecimento, apreciar, julgar, avaliar, reconhecer; contextualizar: apresentar o tempo e o lugar, descrever o contexto de algo; construir: formar, conceber, elaborar. compreender: apreender o sentido de; descrever: fazer a descrição de, expor, contar ou escrever minuciosamente sobre; diferenciar: comparar, estabelecer pontos de convergência e/ou divergência entre; elaborar: preparar pouco a pouco com cuidado, precisão, tornar mais complexo, produzir, formar; entender: apreender, ter conhecimento de, saber; explicar: tornar inteligível ou claro, justificar, entender, compreender, dar a conhecer a origem ou motivo de. Dar explicação ou justificação; identificar: determinar a identidade de. tornar idêntico; inferir: concluir pelo raciocínio por meio de indícios, fatos, deduzir; interpretar: explicar, aclarar o sentido, considerar; ordenar: colocar em certa ordem, organizar; reconhecer: conhecer de novo, admitir como certo, certificar-se de, constatar, verificar, examinar a situação de, observar, explorar, caracterizar; representar: simbolizar, expor verbalmente ou por escrito; relacionar: referir, narrar, relatar, dar ou fazer relação de, por em lista, arrolar, estabelecer relação, analogia. situar: por em certo lugar, posicionar, determinar 
lugar certo a, localizar; solucionar: dar solução a, resolver; valorizar: dar ou reconhecer o valor, a importância de.

No tocante à justificativa da pesquisa, esta decorre do engajamento teórico, do compromisso social e dirige os alvos teóricos e práticos da pesquisa. Segundo Abramo (1979, p. 60), a escolha do tema deve ser encarada como um "fato social em si, e que pode também ser explicada sociologicamente". Nas dissertações e teses avaliadas, registrou-se apenas se a pesquisa apresentava explicação ou descrição da sua relevância social e importância em relação à área de concentração e/ou linha de pesquisa do programa. Dos 61 trabalhos avaliados, 55 apresentam justificativas teóricas e/ou aplicadas $(90,1 \%)$ e seis não apresentam $(9,9 \%)$. O ato de justificar a pesquisa está diretamente relacionado ao porquê de a pesquisa ser realizada. Embora o pesquisador possa apresentar sua justificativa pessoal, deve atentar principalmente para a sua relevância científica e aderência em relação à área de concentração e linha de pesquisa do programa de pós-graduação em questão. Cabe salientar que pesquisas como dissertações e teses requerem certos graus de ineditismo. Portanto, cabe ao pesquisador explicitar o que há de inovador em sua pesquisa.

\subsection{Referencial teórico}

Esta categoria trata de dimensões que identificam a fundamentação teórica utilizada e a relevância para a linha de pesquisa Mídia e Estratégias Comunicacionais. Dos 61 trabalhos avaliados, verificamos que 31 discutem o conceito de estratégia, enquanto 30 não discutem. Convém acentuar que esse indicador desperta uma certa preocupação, já que a linha de atuação tem a estratégia como conceito central.

Conforme evidenciado pelo Gráfico 2, os principais tipos de estratégia contemplados pelos autores são "comunicacional" (31,1\%), "discursiva" (19,7\%) e "comunicacional e discursiva" (11,5\%). Na sequência, "publicitária" (3,3\%) e outros tipos com apenas uma ocorrência cada, representando, 26,2\% do corpus. Alguns exemplos são: “estratégia midiática", "estratégia de enunciação" e "estratégia de legitimação". Os trabalhos restantes, correspondendo a $8,2 \%$, não delimitam tipos específicos de estratégia. 


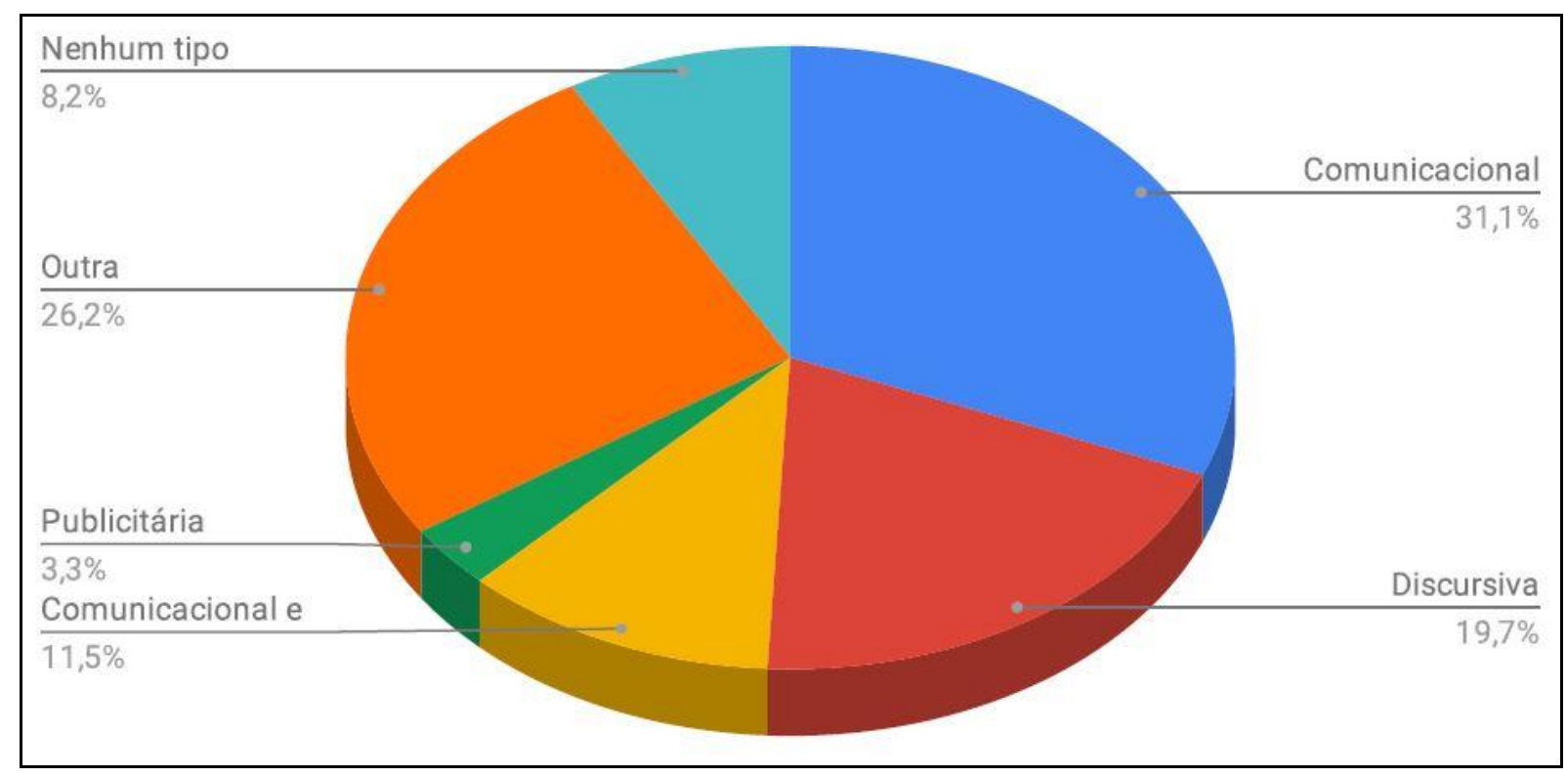

Gráfico 2 - Tipos de estratégias

Fonte: elaborado pelos autores.

No Gráfico 3, apresentamos os autores mais citados sobre o construto estratégia, a saber: Pérez (18,6\%); Mintzberg (11,9\%); Saad (8,5\%); Tzu (6,8\%); Certeau (6,8\%); Morin (3,4\%); Charaudeau e Maingueneau (3,4\%); Porter (3,4\%); Baldissera (3,4\%); Maquiavel $(3,4 \%)$; Greimas $(3,4 \%)$. Os autores restantes tiveram apenas uma ocorrência cada, representando o percentual de $27,1 \%$.

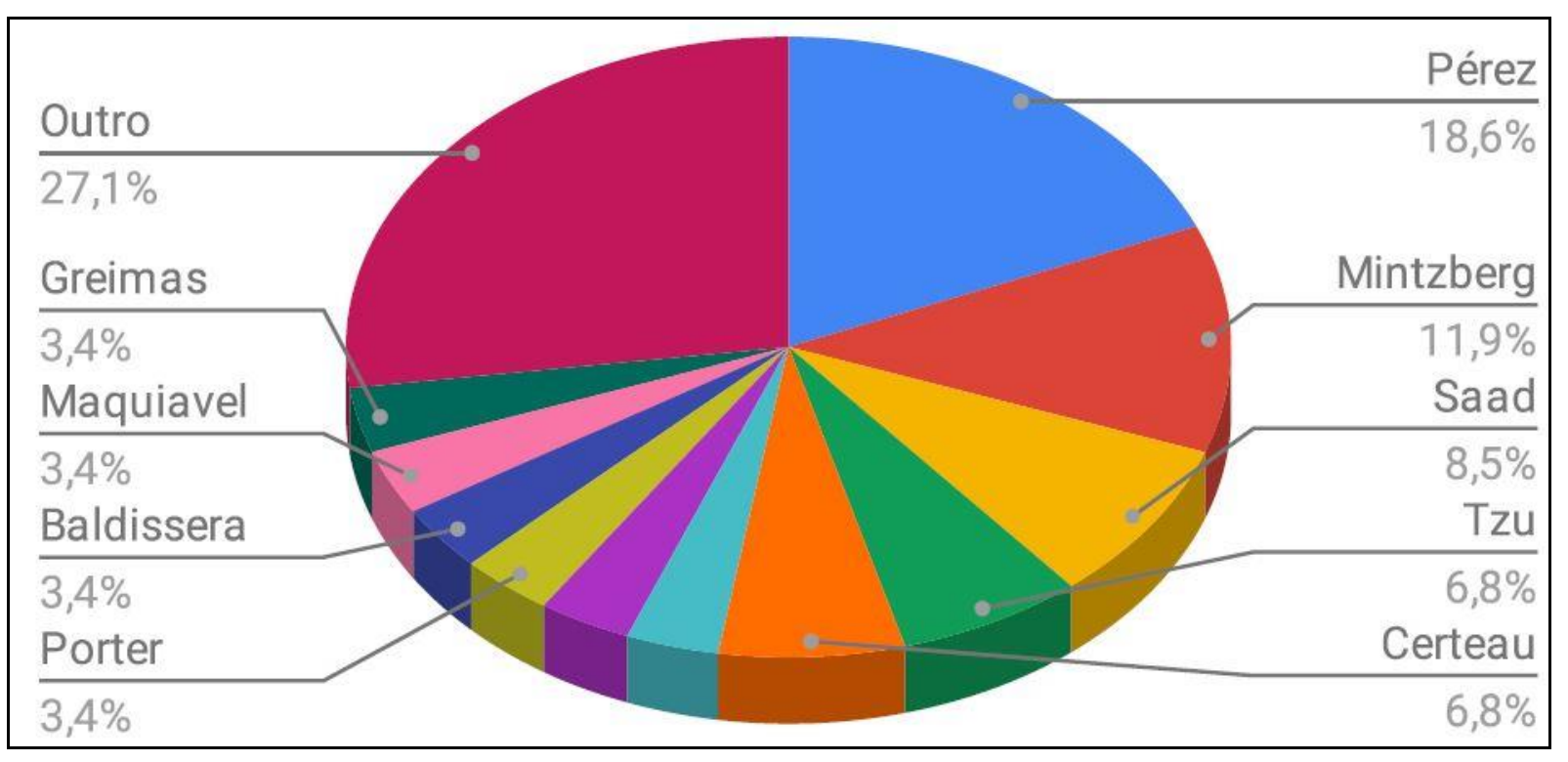

Gráfico 3 - Distribuição de autores citados

Fonte: elaborado pelos autores. 
Já o Gráfico 4 apresenta as áreas de conhecimento dos autores acionados para fundamentar o conceito de estratégia, contemplando: comunicação (40,9\%); administração $(22,7 \%)$, sociologia $(15,9 \%)$, linguística $(9,1 \%)$, militar $(9,1 \%)$ e política $(2,3 \%)$.

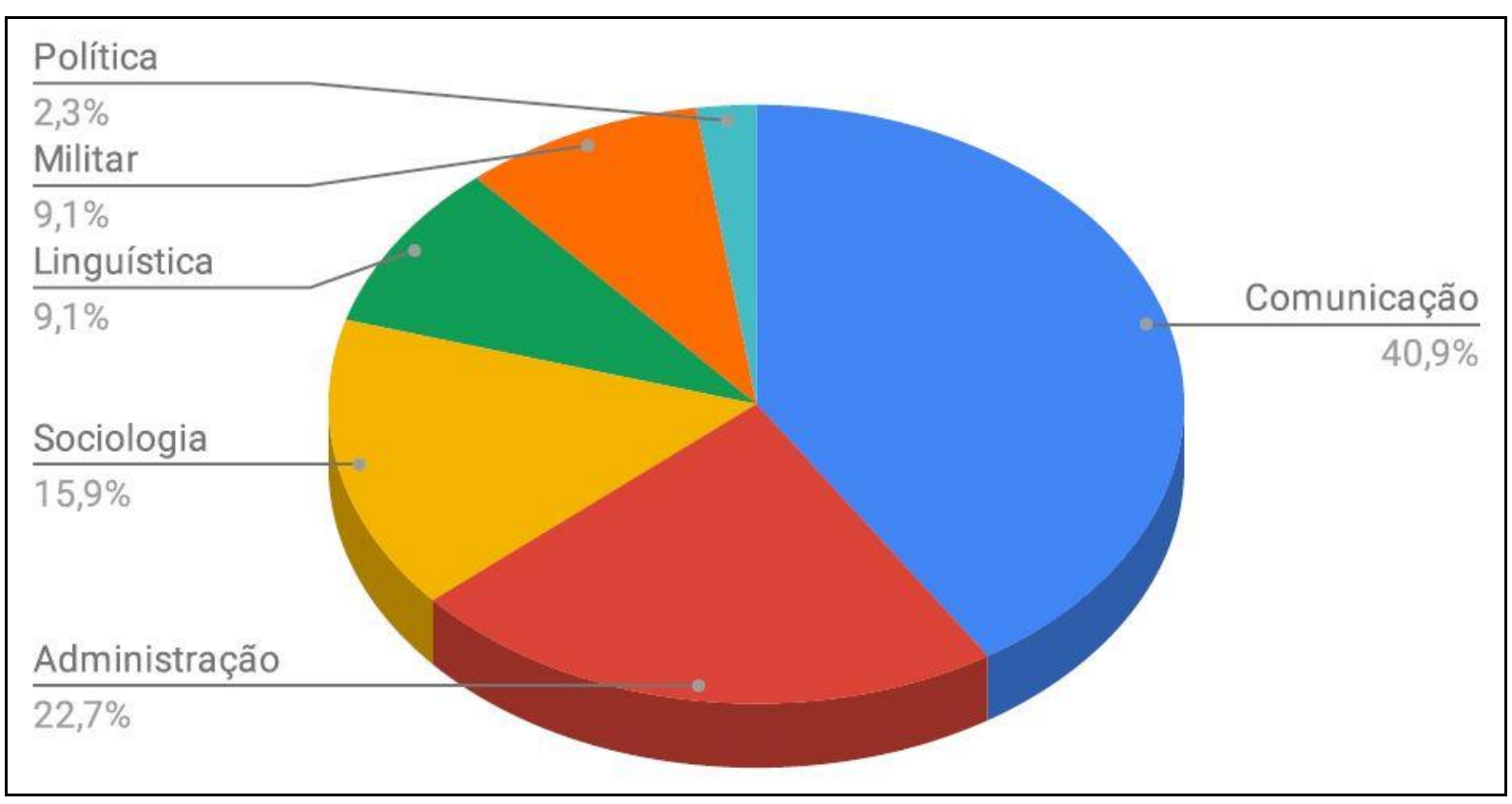

Gráfico 4 - Áreas de conhecimento dos autores citados Fonte: elaborado pelos autores.

Segundo Pérez (2012), para que uma comunicação seja estratégica ela precisa: a) ser concebida para atingir um determinado objetivo futuro; b) ser estruturada de acordo com alguns objetivos descritos nos parâmetros de comunicação (o significado que deseja gerar, por exemplo); c) ser resultado de um pensamento complexo (buscar mais articulação que persuasão, escutar e dialogar, servir de lugar de encontro e geração de significação e de sentido compartilhado e espaço, dentre outros). Uma definição de que estratégia estamos nos referindo se torna imprescindível para fundamentar a interpretação dos dados e fatos colhidos ou levantados. Diante disso, a expressão "estratégia de comunicação" não pode ser tida como um "guarda-chuva" que corresponde a todos os usos, práticas e processos comunicacionais que um indivíduo ou organização delibera, mas sim que permita esclarecer o fenômeno investigado e ter a possibilidade de apresentar os resultados de forma clara e aceita pela comunidade científica. Uma vez que a pesquisa se torna capaz de demonstrar contradições ou reafirmar comportamentos e atitudes, podemos afirmar que tanto a confirmação quanto a enumeração das discrepâncias são de grande importância não apenas na descrição, mas no desenvolvimento de um caráter interpretativo dos fatos colhidos ou levantados empiricamente. 


\subsection{Procedimentos metodológicos - métodos e técnicas de pesquisa}

A instância metódica é o lugar da objetivação. Contempla a fase de exploração de campo, incluindo a escolha do espaço da pesquisa, os critérios e as estratégias para a escolha do grupo/sujeitos de pesquisa, a definição de métodos, técnicas e instrumentos para a coleta de dados e os procedimentos para análise do corpus. Com efeito, são os métodos que fornecem os quadros de análise.

Conforme o Gráfico 5 indica, os métodos empregados pelos discentes da linha de pesquisa Mídia e Estratégias Comunicacionais correspondem a 14 análises semióticas (23\%), 12 estudos de caso (19,7\%), 10 mixes de métodos (16,4\%), cinco análises de discurso $(8,2 \%)$, quatro análises de conteúdo $(6,6 \%)$, duas análises de redes sociais $(3,3 \%)$ e 14 empregam outros métodos $(23,0 \%)$.

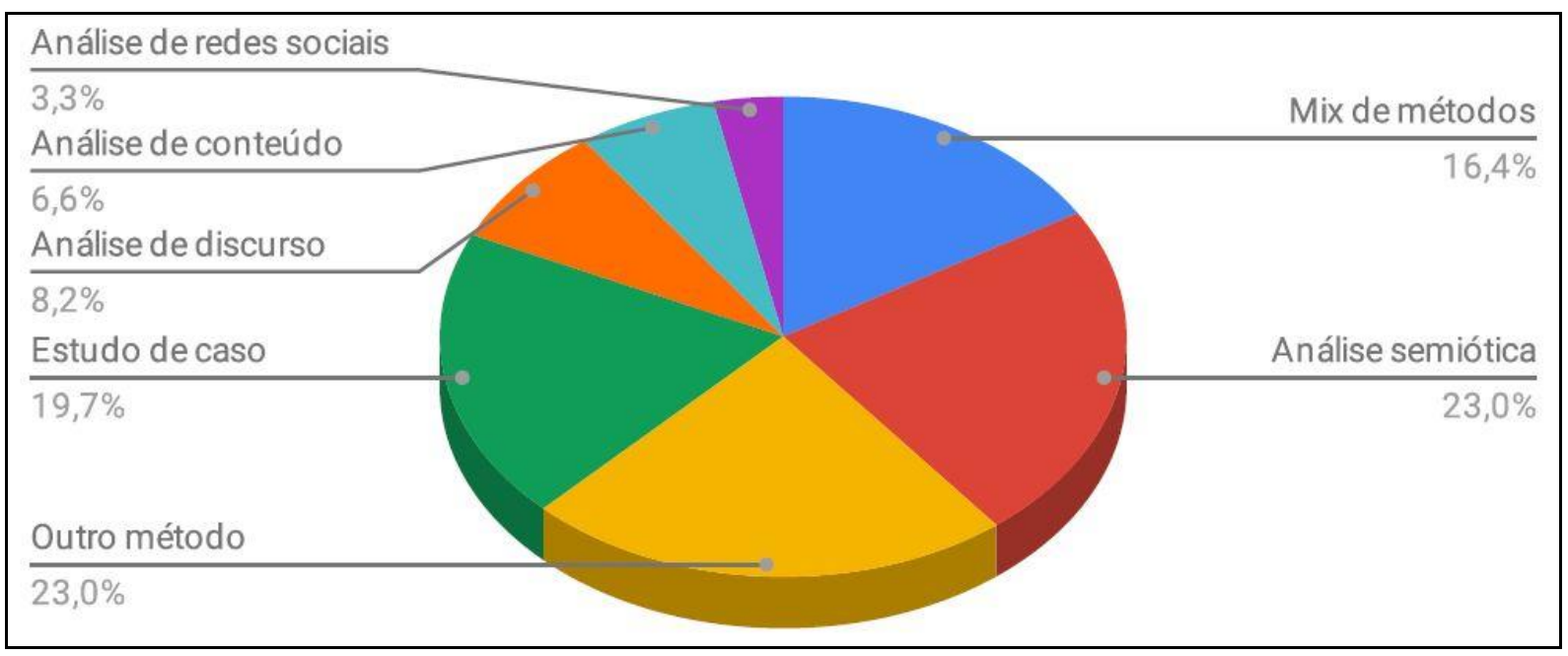

Gráfico 5 - Métodos de pesquisa

Fonte: elaborado pelos autores.

No tocante aos mixes de métodos, estes compreendem as seguintes combinações mencionadas pelos autores: "Teoria da Imagem e Análise do Discurso" (1); "Estudo de Caso e Análise de Conteúdo" (1); "Estudo Comparativo de Casos e Análise de Conteúdo" (1); “Análise do Discurso e Semiologia do Discurso" (1); "Estudo de Caso e Análise Semiótica" (1), "Estudo de Casos Múltiplos, Análise do Discurso e Análise Semiótica” (1); “Observação exploratória, Análise de Redes Sociais e Análise Semiolinguística” (1); “Análise estrutural das Redes Sociais e Análise comparada" (1); "Sociossemiótica e Análise de dados digitais" (1); "Estudo de Caso e Análise do contrato de comunicação" (1).

Os outros métodos indicados pelos autores incluem: "Pesquisa empírica mediada por computador" (2); "Análise indireta dos enquadramentos" (2); "Análise textual com base no 
referencial teórico apresentado" (1); "Observação e descrição dos modos de interação na internet" (1); "Observação" (1); "Modelo construído a partir do contrato de comunicação de Charaudeau (2006)" (1); “Teoria da Imagem" (1); "Planilha para classificação do grau de democracia digital” (1); “Teoria de Newsmaking” (1); “Análise Global de Periódicos Jornalísticos (AGPJ)” (1); “Cartografia” (1); “Análise Semiolinguística” (1).

Ademais, dos 61 trabalhos analisados, 12 não detalham os procedimentos metodológicos $(19,6 \%)$, sendo que oito deles foram concluídos no período de 2008 a 2012, que correspondem aos primeiros cinco anos de produção efetiva do Poscom. Nesse sentido, essa fragilidade pode ter relação com o processo gradual de maturação do programa.

No que diz respeito às técnicas de coletas de dados, dos 61 trabalhos, 26 utilizaram documentos (incluindo mídias), 24 aplicaram mixes de técnicas, 10 recorreram à observação não-participante e um trabalhou com questionário. Dos 19 autores que utilizaram técnicas para coleta de dados tais como questionários e entrevistas, nenhum relatou ter previamente testado esses instrumentos.

\subsection{Indicativos relativos às considerações finais dos trabalhos}

Como última etapa das análises, direcionamos nossos olhares para as considerações finais dos trabalhos, a fim de verificar se os autores apresentaram os limites dos estudos e as recomendações para pesquisas futuras.

Dos 61 trabalhos analisados, 32 apresentam os limites do estudo, enquanto 29 não procedem de igual modo, sendo que a maior parte das pesquisas que não apresenta está concentrada nos anos iniciais do Poscom - fato que pode, novamente, estar relacionado ao processo gradual de maturação do programa. A importância de apresentar as limitações do estudo reside na constatação de que, eventualmente, mesmo com o esforço pessoal e aplicação dos métodos adequados, o pesquisador pode enfrentar adversidades não previstas, como pouco conhecimento teórico sobre o fenômeno, falta de tempo hábil para realizar todas as análises propostas no início do percurso e dificuldades para coletar dados, a exemplo de quando uma empresa se recusa a ceder o acesso a documentos importantes. Ademais, ainda que tudo saia de acordo com o planejado, toda pesquisa apresenta seus limites intrínsecos, pois não é possível esgotar um objeto ou tema por meio de um único estudo. Assim, cabe ao pesquisador apresentar quais são os limites do seu trabalho.

Quanto às recomendações para outras pesquisas, dos 61 trabalhos avaliados, 33 apresentam indicações para futuras pesquisas, enquanto 28 procedem de modo contrário, 
sendo que, das 12 teses analisadas, apenas três não apresentam. Essa descoberta pode apontar para uma maior preocupação, por parte dos doutorandos, com a perpetuidade científica, especialmente relacionada aos fenômenos investigados em suas pesquisas.

Por fim, apuramos se as recomendações eram de natureza teórica ou aplicada. Nessa perspectiva, somente sete dos 61 trabalhos analisados apresentam recomendações aplicadas. Essa realidade se aplica, principalmente, a estudos relacionados a organizações, nos quais os autores recomendam ações práticas para que elas possam repensar os seus processos de comunicação.

\section{CONSIDERAÇÕES}

A principal contribuição deste artigo consiste em apresentar um quadro abrangente da produção científica da linha de pesquisa Mídia e Estratégias Comunicacionais, do Programa de Pós-Graduação em Comunicação, da Universidade Federal de Santa Maria (UFSM), referente à sua primeira década de produção efetiva (2008-2017). Possivelmente, o estudo permitirá reorientar as linhas de pesquisa do Poscom e também acelerar a consolidação do programa e a busca do conceito 6 da CAPES.

A análise revelou uma unanimidade de estudos empíricos, sendo, em sua maioria, organizações midiáticas. Destaca-se, também, o elevado percentual de pesquisas qualitativas de natureza exploratória. Quanto a esta, consideramos que é apropriada para qualquer problema ou fenômeno sobre o qual pouco se sabe, servindo como fundamentação para futuros estudos.

Na pesquisa foram ainda exploradas particularidades como a apresentação da questão de pesquisa, hipóteses, objetivos e justificativa, as abordagens metodológicas, as indicações dos limites dos estudos e as recomendações para pesquisas futuras. De modo geral, as pesquisas demonstram preocupação com a apresentação e a relevância da problemática de estudo. Nesse sentido, cabe frisar que o problema de pesquisa vem a ser um conjunto de proposições que estabelecem relações entre conceitos. Estes são transformados em indicadores empíricos ou unidades observáveis que, junto com as hipóteses, permitem construir os instrumentos técnicos da fase seguinte, que compreende a escolha do conjunto específico e concreto a ser observado ("recorte", corpus, amostra, grupo, documentos, situações, pessoas etc.). Embora o levantamento de hipóteses não seja uma prática comum em pesquisas do tipo qualitativo, observamos que elas são apresentadas em 16 trabalhos, correspondendo a $26,2 \%$. Por outro lado, somente um trabalho não apresentou o seu objetivo 
geral, o que pode ser considerado como um indicador positivo, na medida em que os demais pesquisadores explicitam o que pretendem alcançar com suas investigações científicas.

Em relação ao referencial teórico, a pesquisa procurou identificar se o conceito de estratégia estava presente ou ausente e quais teorias e autores alumiaram os processos de investigação dos discentes. Nesse processo, constatamos que quase metade dos trabalhos não apresenta o conceito, evidência que desperta certa preocupação, pois, em um estudo científico, o teor de qualquer enfoque qualitativo a ser desenvolvido será dado pelo referencial teórico no qual se apoia o pesquisador.

Em concordância com Triviños (1994), muitas das dificuldades que os mestrandos e doutorandos encontram na elaboração de suas dissertações ou teses residem no aspecto da fundamentação teórica, também chamada de referencial teórico, revisão de literatura etc. $\mathrm{O}$ autor reforça que, em um cenário ideal, o pesquisador deve se guiar por determinadas formulações conceituais que integram as teorias e que iluminam os fatos observados, indicando os métodos, os instrumentos de coleta de dados, os informantes e os tipos de perguntas mais pertinentes para análise de algum fenômeno social, da intuição da existência de fatos no mundo real ou da relação dos mesmos.

Com base nos dados levantados, observamos, ainda, uma pluralidade de métodos empregados nos trabalhos da linha de pesquisa Mídia e Estratégias Comunicacionais. Sem entrar no mérito da consistência dos métodos indicados pelos autores ou da pertinência dos seus usos, tampouco na questão da coesão de se combinar métodos de perspectivas epistêmicas distintas, julgamos importante evidenciar a abertura dos discentes e docentes acerca da introdução de diversas abordagens metodológicas, o que pode refletir a característica interdisciplinar do campo da comunicação. Afinal, trata-se de uma área que se constitui a partir da composição teórica e metodológica de outras ciências, como a Sociologia e a Linguística.

Por fim, como pesquisas futuras a serem realizadas a partir deste estudo, sugerimos uma comparação com as dissertações e teses da linha de pesquisa Mídia e Identidades Contemporâneas, do Poscom/UFSM, e também com estudos realizados em outros programas de pós-graduação em comunicação no Brasil e em países distintos, permitindo cotejar os temas, autores, metodologias, tendências e preocupação com o rigor científico no desenvolvimento das pesquisas. 


\section{REFERÊNCIAS}

BRAGA, José Luiz. A prática da pesquisa em Comunicação: abordagem metodológica como tomada de decisões. Revista da Associação Nacional dos Programas de Pós-Graduação em Comunicação | E-compós. Brasília, v.14, n.1, jan./abr. 2011.

BRASIL. Instituto Nacional de Estudos Pedagógicos Anísio Teixeira. Banco Nacional de Itens, 2011.

CAPES. Aplicativo para Propostas de Cursos Novos - APCN. Programa de Pós-Graduação em Comunicação, UFSM, 2006. Disponível em: <http://www.capes.gov.br/avaliacao/cursosnovos-enviode-propostas-e-resultado)>. Acesso em: 03 ago. 2020.

GIL, Antonio Carlos. Métodos e Técnicas de Pesquisa Social. 4. Ed. São Paulo: Atlas, 1994

LOPES, Maria Immacolata Vassallo de. Pesquisa em Comunicaçãa: formulação de um modelo metodológico. São Paulo: Edições Loyola, 1990.

PÉREZ, Rafael Alberto. El estado del arte en la Comunicación Estratégica. Mediaciones Sociales, Madri, n. 10, p. 121-196, 2012. Disponível em:

<http://revistas.ucm.es/index.php/MESO/article/view/39684>. Acesso em: 15 jul. 2018.

PERSEU, Abramo. Pesquisa em Ciências Sociais. In: HIRANO, Sedi (org.), Pesquisa Social: projeto e planejamento. São Paulo: T.A. Queiroz, 1979.

TRIVIÑOS, Augusto N. S. Introdução à Pesquisa em Ciências Sociais: a pesquisa qualitativa em educação. São Paulo: Atlas, 1987.

Original recebido em: 01 de agosto de 2020

Aceito para publicação em: 01 de setembro de 2020

Maria Ivete Trevisan Fossá

Professora do Departamento de Comunicação e do Programa de Pós-Graduação em Comunicação da

Universidade Federal de Santa Maria (UFSM), com pós-doutorado na Universidade Nacional de Quilmes/Argentina. Líder do Grupo de Pesquisa Comunicação Institucional e Organizacional/CNPq.

\section{Mateus da Cunha Santos}

Mestre em Comunicação pelo Programa de Pós-Graduação em Comunicação da Universidade Federal de Santa Maria (UFSM). Membro do Grupo de Pesquisa Comunicação Institucional e Organizacional/CNPq. 
Doutorando em Comunicação, na linha de pesquisa Mídia e Estratégias Comunicacionais, do Programa de Pós-Graduação em Comunicação da UFSM. Membro do Grupo de Pesquisa Comunicação Institucional e Organizacional/CNPq.

Kauane Andressa Müller

Mestra em Comunicação pelo Programa de Pós-Graduação em Comunicação da UFSM. Membro do Grupo de Pesquisa Comunicação Institucional e Organizacional/CNPq.

Amanda Frick Martins

Doutoranda em Comunicação, na linha de pesquisa Mídia e Estratégias Comunicacionais, do Programa de Pós-Graduação em Comunicação da UFSM. Membro do Grupo de Pesquisa Comunicação Institucional e Organizacional/CNPq.

Solange Prediger

Doutoranda em Comunicação, na linha de pesquisa Mídia e Estratégias Comunicacionais, do Programa de Pós-Graduação em Comunicação da UFSM. Membro do Grupo de Pesquisa Comunicação Institucional e Organizacional/CNPq.

Gibsy Lisiê Soares Caporal

Doutoranda em Comunicação, na linha de pesquisa Mídia e Estratégias Comunicacionais, do Programa de Pós-Graduação em Comunicação da UFSM. Membro do Grupo de Pesquisa Comunicação Institucional e Organizacional/CNPq.

\section{Taisa Ferro Dalla Valle}

Doutoranda em Comunicação, na linha de pesquisa Mídia e Estratégias Comunicacionais, do Programa de Pós-Graduação em Comunicação da UFSM. Membro do Grupo de Pesquisa Comunicação Institucional e Organizacional/CNPq.

\section{@ $\odot \Theta \odot$}

Esta obra está licenciada com uma Licença

Creative Commons Atribuição-NãoComercial-CompartilhaIgual 4.0 Internacional 